\title{
THE INFLUENCE OF THE DISTRIBUTOR PLATE ON THE BOTTOM ZONE OF A FLUIDIZED BED APPROACHING THE TRANSITION FROM BUBBLING TO TURBULENT FLUIDIZATION
}

\author{
J. M. PAIVA ${ }^{1}$, C. PINHO ${ }^{2}$ and R. FIGUEIREDO ${ }^{3}$ \\ ${ }^{1}$ Mechanical Engineering and Industrial Management Department, ESTV, Polytechnic of Viseu, Viseu, Portugal \\ ${ }^{2}$ CEFT-DEMEGI, Faculty of Engineering, University of Oporto, Oporto, Portugal \\ ${ }^{3}$ Mechanical Engineering Department, Faculty of Science and Technology, University of Coimbra, Coimbra, Portugal
}

$\mathrm{T}$ he dynamics of the bottom zone of a narrow fluidized bed, from bubbling to turbulent regimes, was studied in a cold model of $0.1 \mathrm{~m}$ i.d. and $1.3 \mathrm{~m}$ high. Tested distributor types were perforated perspex plates, with six different perforation grids, metallic mesh and porous ceramic, with pressures drops ranging from 0.05 to $350 \mathrm{kPa}$, corresponding to superficial air velocities from 0.1 to $2.3 \mathrm{~m} \mathrm{~s}^{-1}$. Group B silica ballotini, within the range $0.355-$ $0.425 \mathrm{~mm}$, were used as bed material. The experimental data consisted of pressure drop and absolute pressure fluctuating signals, together with visual observations. The bottom zone presented a dynamic condition that produced higher pressure drop values than those expected with the incipient fluidization condition, particularly for the distributor plates with a higher open area. A simple model is used to describe the axial solids distribution and the dynamics characteristics of the voids created in that zone, and an attempt is made to differentiate the bubble voidage from that of the dense phase, with a value of through flow estimated in a systematic way.

Keywords: fluidization regimes; bottom zone; distributor plate.

\section{INTRODUCTION}

The performance of a gas distributor is very important to the success of the operation of a fluidized bed (Geldart and Baeyens, 1985). The present work analyses the influence of some distributor types (porous ceramics, metallic mesh and perforated perspex), under different fluidization velocities, covering bubbling and turbulent regimes, on the bottom zone of a fluidized bed using Group B silica ballotini within the size range 0.355$0.425 \mathrm{~mm}$. Although the bottom zone represents only a small part of the bed, it is of considerable importance in what concerns the reactions taking place in a fluidized bed reactor, owing to the high solids concentration and the retention of the reactants (Schlichthaerle and Werther, 1999). Svensson et al. (1993), based on experimental values of the pressure profile, defined the height of the bottom zone as the level at which that profile starts to deviate from a straight line. Schlichthaerle and Werther (1999) proposed that it should be defined as the height of the column where the solid concentration begins to decrease.

*Correspondence to: Dr J. M. Paiva, Departmento de Engenharia Mecânica e Gestão Industrial, Escola Superior de Tecnologia, Campus Politécnico, 3504-510 Viseu, Portugal.

E-mail: jmonney@demgi.estv.ipv.pt
As for the hydrodynamic structure of that region of the bed, some authors consider it to be core-annulus type (Sun et al., 1999), others cluster-like (Brereton and Grace, 1993), bubbling at all times (Werther and Wein, 1994; Svensson et al., 1996a), turbulent (Schnitzlein and Weinstein, 1988; Bolton and Davidson, 1988; Bai et al., 1996), or with a turbulent core region and a dense bubbling condition at the wall (Schlichthaerle and Werther, 1999). Finally, Malcus et al. (2000), using an electrical capacitance tomography method, found no significant change of the hydrodynamic behaviour of the gas-solid suspension, measured between two different heights inside the bed. As for the influence of the distributor plate, apart the work of Svensson et al. (1996b), no other references were found to the way it might affect the bottom of the bed, either from the point of view of the different type of used plates, or concerning the pressure drop across the distributor. Several authors considered a constant voidage at the bottom bed, extrapolating the pressure drop profile between the lowest pressure tap and the distributor (Johnsson and Leckner, 1995; Zijerveld et al., 1997), or found no inflexions of voidage (Malcus et al., 2000).

Some experimental results concerning the changes occurring in the fraction of solids with height are also examined. Different velocities and eight different types of distributor plates were used in the experiments. A technique to estimate the porosity fluctuations of the dense phase, in the bottom of the bed is also proposed. 

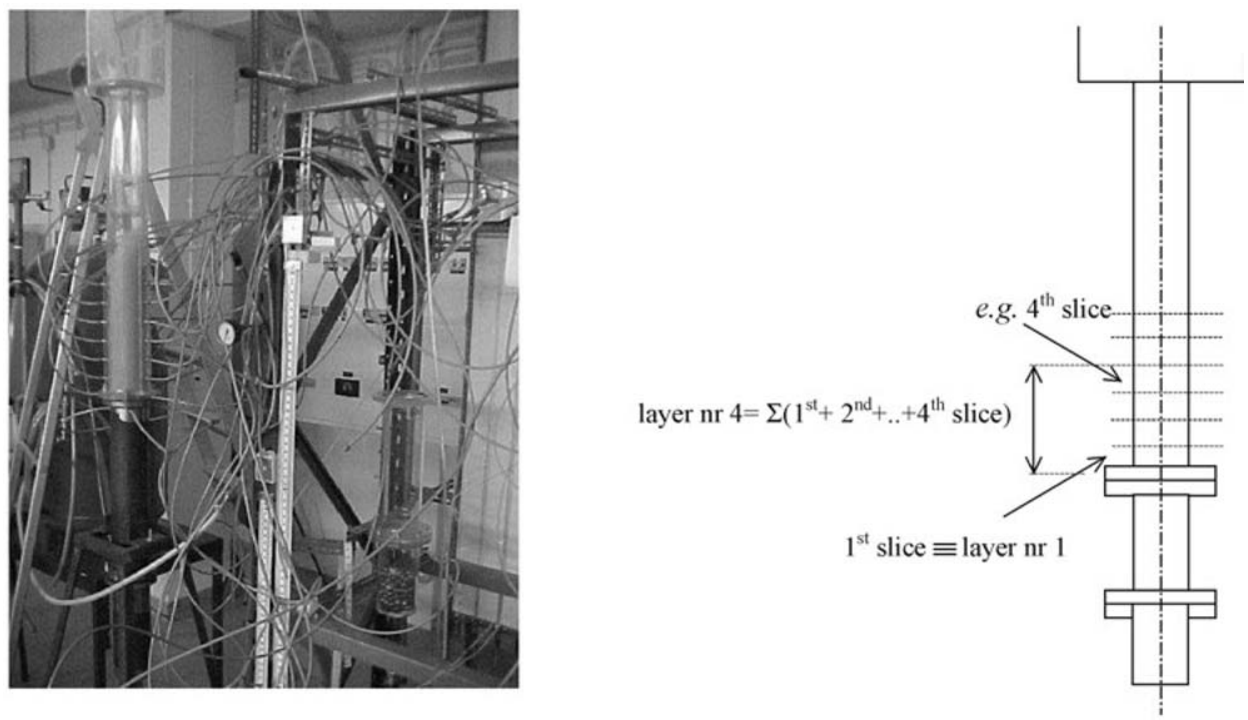

Figure 1. Photo where the location of the several pressure taps can be observed and schematics of the experimental setup.

\section{EXPERIMENTAL}

The experimental work was done in a cold, atmospheric fluidized bed, with a $100 \mathrm{~mm}$ internal diameter perspex tube, using air at ambient conditions as the fluidizing medium (Figure 1).

The fluidized bed was established by fluidizing Group B silica ballotini, 355-425 $\mu \mathrm{m}$, previously screened from bulk samples and then statistically assessed with $t$-tests to evaluate the consistency of the means, using SPSS $^{\circledR}$ software package, as well as a Coulter LS 230 Particle Size Analyser. The airflow rate was measured with orifice plate flowmeters, equipped with a Furness Control FCO18 differential pressure transducer, connected to a data acquisition system.

Instead of measuring the evolution of the whole bed pressure drop, a different approach was followed. The $300 \mathrm{~mm}$ bed static height was divided into horizontal slices. The pressure measurements were made at each one of the six horizontal slices of $50 \mathrm{~mm}$ high the bed was divided in. The experimental conditions are summarized in Table 1.

Three pressure probes were used at each level, placed at angular intervals of $120^{\circ}$ (Figure 2). The data acquired represented cumulative values for each layer, i.e. the values of the first layer represent the slice ' 1 ' pressure drop, the values of the second layer the slice ' 1 plus 2 '

Table 1. Experimental conditions.

\begin{tabular}{lc}
\hline Data on the experimental setup & Value \\
\hline Internal bed diameter, $D(\mathrm{~m})$ & 0.10 \\
Height of the unit, $L(\mathrm{~m})$ & 1.8 \\
Local atmospheric pressure, $P(\mathrm{~Pa})$ & 97500 \\
Bed temperature, $T\left({ }^{\circ} \mathrm{C}\right)$ & 15 \\
Fluidization velocity, $U_{0}\left(\mathrm{~m} \mathrm{~s}^{-1}\right)$ & $0.1-2.3$ \\
Bed material & Silica ballotini \\
Bed material density, $\rho_{\mathrm{p}}\left(\mathrm{kg} \mathrm{m}^{-3}\right)$ & 2485 \\
Average particle diameter $d_{\mathrm{p}}=1 /\left(\sum x_{i} / d_{\mathrm{p} i}\right)(\mu \mathrm{m})$ & 372 \\
Minimum fluidization velocity, $U_{\mathrm{mf}}\left(\mathrm{m} \mathrm{s}^{-1}\right)$ & 0.1 \\
Static bed height, $H(\mathrm{~m})$ & 0.3 \\
\hline
\end{tabular}

pressure drop, and so on until the sixth layer, corresponding to the sum of the measured pressure drops from slices 1 to 6 . Each probe was calibrated against U-tube water pressure manometers. Values for the pressure drop of each slice were recorded for consecutively decreasing flowrates, using Furness Control differential transducers FCO15 and 16 and Klay Peramic pressure transmitters CER8000, connected to a data acquisition system. Problems with pressure taps plugging were inexistent as the porosity of the particles avoided it and a set of two consecutive U-bends (one up and one down) was used after each tap to prevent damage to the pressure transmitters' membranes. Figure 3 shows a typical example of the pressure measured by a probe located in the fifth layer and of the differential pressure signal measured between two probes (second and third, slice 2).

The data acquisition system used a sampling frequency of $5 \mathrm{~Hz}$. To ensure sufficient accuracy in the statistical analysis, an average of 1000 samples were taken for each spectrum; those readings were then weighed in order to output values corresponding to arithmetically averaged $1 \mathrm{~s}$ intervals. Later on, using a suitable program, these were determined for each position of the flowmeter and the dubious points eliminated according to Chauvenet's criterion (Holman, 1994).

The plate's pressure drop evolution for the tested gas flow range for each distributor type was measured with pressure probes calibrated against U-tube mercury pressure manometers. Eight different distributors were used: six perforated perspex plates, one metallic mesh and one porous ceramic, with pressures drops ranging from 60 to $300 \mathrm{kPa}$, and superficial gas velocities going from 0.1 to $2.3 \mathrm{~m} \mathrm{~s}^{-1}$ at standard pressure and temperature. The relevant data for the distributors is given in Table 2. A more extensive description of the experimental setup can be found in Paiva et al. (2000).

The uncertainty calculations follow the Coleman and Steele (1999) systematic approach. It consists in using a detailed analysis by means of an evaluation of the fixed or systematic, and random or precision contributions, for each of the measured variables, thus obtaining values of the fixed 


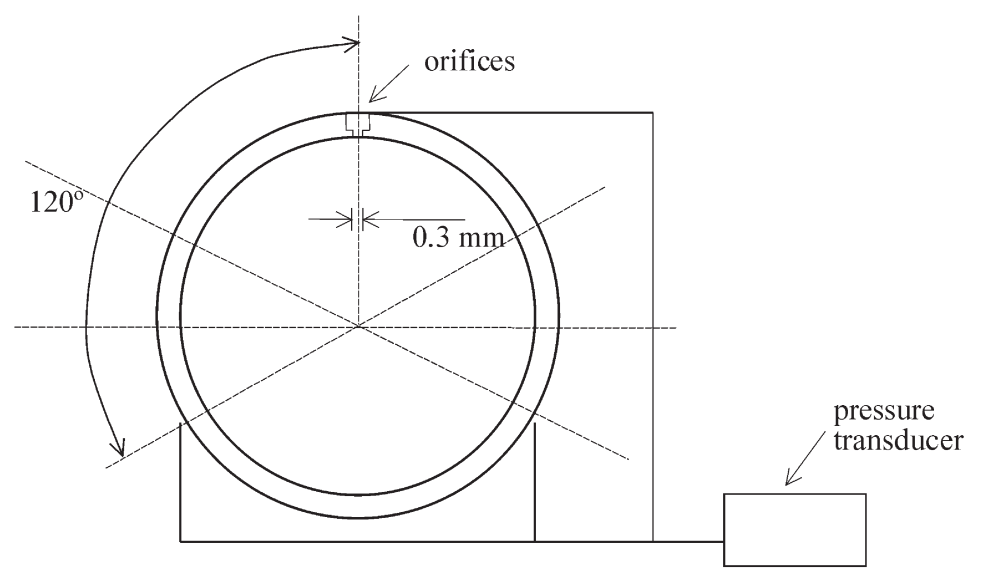

Figure 2. Radial distribution of pressure tap for each slice.

(a)

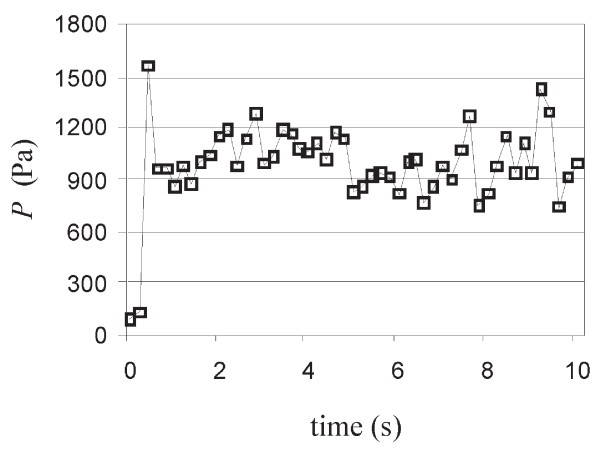

(b)

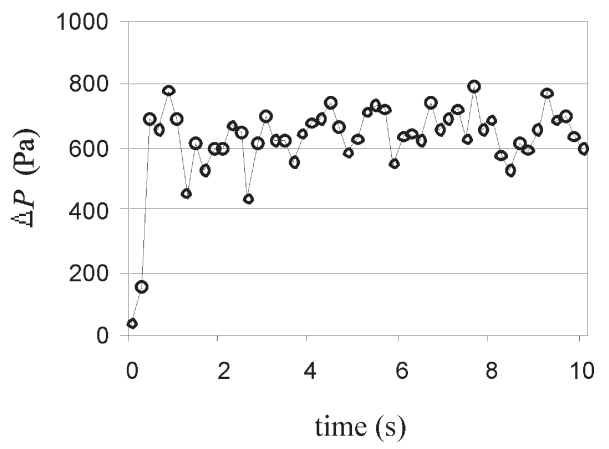

Figure 3. Time sequence of, for example, pressure measured by a probe located on the top of (a) the fifth layer and (b) a differential transducer measuring the pressure drop in the second slice.

uncertainty $I_{\mathrm{Fr}}$, and of the random uncertainty $I_{A r}$, concerning the experimental result. As the focus is on the axial evolution of the bed of solids, it was important to analyse the pressure evolution with height as an indirect measure of the solids fraction. Therefore, the uncertainty analysis carried out was based on the acquired values of pressure and the calculation of the pressure drop of the successive layers, as well as on the measurement of the other variable, the superficial velocity, which was evaluated for increasing values within the range from incipient fluidization to the maximum experimentally allowed value for that setup.

Table 3 presents the values for the standard deviation $\sigma$, fixed $I_{\mathrm{F} \Delta P_{i}}$, random $I_{\mathrm{A} \Delta P_{i}}$, and global $I_{\Delta P_{i}}$ uncertainties, associated to each layer pressure drop. In order to obtain the uncertainties, three fixed errors were considered: the calibration process error for the pressure transducers, the analog-to-digital conversion and the hardware precision indicated by the manufacturer. The final value is the square root of the sum of the squares of each contribution. As for the random contribution, errors arising from calibration and from statistical reading of the acquisition data system were considered, the final result being calculated as described previously for the fixed uncertainty. Table 4 shows the uncertainty values regarding the fixed $I_{\mathrm{F}}$, random $I_{\mathrm{A}}$, and global $I$ uncertainties, for the range of superficial velocities, from $U_{\mathrm{mf}}$ to maximum $U_{0}$, taking into consideration variables such as the thin plate orifice pressure drop, the gas temperature, the gas constant and the measurement precision of the duct diameter.

Table 2. Data on distributors/orifices.

\begin{tabular}{|c|c|c|c|c|c|c|c|}
\hline Type & $\begin{array}{l}\text { Plate } \\
\text { reference }\end{array}$ & $\begin{array}{l}\mathrm{Nr} \text { of } \\
\text { orifices } \\
N_{\text {or }}\end{array}$ & $\begin{array}{c}\text { Open } \\
\text { area }(\%)\end{array}$ & $\begin{array}{c}\text { Orifice } \\
\text { diameter } \\
d_{\text {or }}(\mathrm{mm})\end{array}$ & $\begin{array}{l}\text { Pressure drop } \\
\text { ratio, } \Delta P_{\text {dist }} / \Delta P_{\mathrm{t}} \text {, } \\
\text { at } U_{\mathrm{mf}}(\%)\end{array}$ & $\begin{array}{l}\text { Maximum } \\
U_{0}\left(\mathrm{~m} \mathrm{~s}^{-1}\right)\end{array}$ & $\begin{array}{c}\text { Pressure drop } \\
\text { ratio, } \Delta P_{\text {dist }} / \Delta P_{\mathrm{t}} \text {, at } \\
\text { maximum } U_{0}(\%)\end{array}$ \\
\hline \multirow{6}{*}{$\begin{array}{l}\text { Perforated plate with } \\
\text { triangular pitch }(\mathrm{p} \# \mathrm{x})\end{array}$} & $\mathrm{p} 0 \mathrm{x}$ & 50 & 0.045 & 0.3 & 946 & 0.6 & 9138 \\
\hline & $\mathrm{p} 1 \mathrm{x}$ & 109 & 0.098 & 0.3 & 418 & 1.0 & 8603 \\
\hline & $\mathrm{p} 2 \mathrm{x}$ & 199 & 0.179 & 0.3 & 180 & 1.2 & 8241 \\
\hline & p3x & 300 & 0.270 & 0.3 & 54 & 1.7 & 7145 \\
\hline & $\mathrm{p} 4 \mathrm{x}$ & 386 & 0.347 & 0.3 & 46 & 2.0 & 5649 \\
\hline & p9x & 948 & 0.853 & 0.3 & 18 & 2.2 & 1400 \\
\hline Metallic mesh (dyn) & dyn & & 0.675 & $O 0.3$ & 23 & 2.2 & 2318 \\
\hline Porous ceramic (ker) & ker & & 8.482 & $O 0.3$ & 1 & 2.3 & 42 \\
\hline
\end{tabular}


Table 3. Standard deviation $(\sigma)$, fixed $\left(I_{\mathrm{F} \Delta P_{i}}\right)$, random $\left(I_{\mathrm{A} \Delta P_{i}}\right)$ and global uncertainties $\left(I_{\Delta P_{i}}\right)$, for the successive layers pressure drop $\Delta P_{i}$

\begin{tabular}{lccccccc}
\hline Layer $i$ & $\sigma(\mathrm{Pa})$ & $I_{\mathrm{F} \Delta P_{i}}(\mathrm{~Pa})$ & $I_{\mathrm{F} \Delta P_{i}}(\%)$ & $I_{\mathrm{A} \Delta P_{i}}(\mathrm{~Pa})$ & $I_{\mathrm{A} \Delta P_{i}}(\%)$ & $I_{\Delta P_{i}}(\mathrm{~Pa})$ & $I_{\Delta P_{i}}(\%)$ \\
\hline 1 & $0.60-9.68$ & 15.11 & 3.08 & 5.11 & 1.04 & 15.95 \\
2 & $0.57-9.05$ & 21.38 & 2.18 & 7.22 & 0.74 & 22.57 & 3.25 \\
3 & $1.01-10.13$ & 26.19 & 1.78 & 8.85 & 0.60 & 27.65 & 1.88 \\
4 & $0.91-14.97$ & 149.58 & 7.62 & 10.21 & 0.52 & 149.92 & 7.64 \\
5 & $0.60-11.13$ & 154.08 & 6.28 & 11.42 & 0.47 & 154.50 & 6.30 \\
6 & $2.11-34.01$ & 249.54 & 8.48 & 12.51 & 0.43 & 249.85 & 8.49 \\
Total & $1.64-25.46$ & 196.29 & 6.67 & 5.11 & 0.17 & 196.36 & 6.67 \\
\hline
\end{tabular}

Table 4. Fixed $\left(I_{\mathrm{F}}\right)$, random $\left(I_{\mathrm{A}}\right)$ and global correlated $(I)$ uncertainties of $U_{0}$ and $U_{\mathrm{mf}}$ range of superficial velocities.

\begin{tabular}{lcccccc}
\hline & $I_{\mathrm{F}}\left(\mathrm{m} \mathrm{s}^{-1}\right)$ & $I_{\mathrm{F}}(\%)$ & $I_{\mathrm{A}}\left(\mathrm{m} \mathrm{s}^{-1}\right)$ & $I_{\mathrm{A}}(\%)$ & $I\left(\mathrm{~m} \mathrm{~s}^{-1}\right)$ & $I(\%)$ \\
\hline$U_{0}\left(2.1 \mathrm{~m} \mathrm{~s}^{-1}\right)$ & 0.00825 & 0.38 & 0.00179 & 0.08 & 0.00845 & 0.39 \\
$U_{0}\left(1.5 \mathrm{~m} \mathrm{~s}^{-1}\right)$ & 0.01290 & 0.61 & 0.00150 & 0.09 & 0.01039 & 0.62 \\
$U_{0}\left(1.0 \mathrm{~m} \mathrm{~s}^{-1}\right)$ & 0.01472 & 1.27 & 0.00137 & 0.12 & 0.01479 & 1.28 \\
$U_{\mathrm{mf}}\left(0.45 \mathrm{~m} \mathrm{~s}^{-1}\right)$ & 0.02461 & 3.55 & 0.00180 & 0.26 & 0.02467 & 3.56 \\
$U_{\mathrm{mf}}\left(0.28 \mathrm{~m} \mathrm{~s}^{-1}\right)$ & 0.03182 & 5.92 & 0.00267 & 0.42 & 0.03190 & 5.93 \\
$U_{\mathrm{mf}}\left(0.1 \mathrm{~m} \mathrm{~s}^{-1}\right)$ & 0.03418 & 6.82 & 0.00243 & 0.48 & 0.03427 & 6.84 \\
\hline
\end{tabular}

In both tables the global value is the square root of the sum of the squares of the fixed and random values and, beyond the indication of the absolute values, a percentage ratio between that absolute value and the range of measurement is also given.

\section{RESULTS AND ANALYSIS}

\section{Solids Concentration at the Bottom of the Bed}

In order to calculate the evolution of the bed axial solids concentration $\varepsilon_{\mathrm{s}}$, the accumulated values of the experimental pressure drop per slice, $\Delta P_{\mathrm{s} j}$, were used so that the sum of successive values will determine the pressure drop of each layer under analysis, from the first to the sixth $\Delta P_{i}$ :

$$
\Delta P_{i}=\sum_{j=1}^{i} \Delta P_{\mathrm{s} j}
$$

Such values of $\Delta P_{i}$ are shown in Figure 4 for two different types of distributor, 'p9x' and 'dyn', for increased values of $U_{0} / U_{\mathrm{mf}}$, from the first to the sixth layer. The curves follow the expected hierarchy among the involved layers. In fact, the more slices are considered, the higher the pressure drop of the corresponding layer, whereas with the increase of $U_{0} / U_{\mathrm{mf}}$ expected discrepancies between layers become progressively reduced with the increase of in-bed mixing.

The approach that is followed is based on the axial evolution of the pressure drop as an indirect step to calculate the bed solids fraction. Following the basic idea of Svensson et al. (1993), who made use of the axial pressure profile to define the height of the bottom zone, the axial values of the solids concentration are calculated from the pressure gradient, considering that the pressure drop is due to the hydrostatic head of solids minus buoyancy, between two differential pressure taps, when the bed is operated under incipient fluidization conditions:

$$
\frac{\mathrm{d} P}{\mathrm{~d} H}=\left(\rho_{\mathrm{p}}-\rho_{\mathrm{f}}\right) g\left(1-\varepsilon_{\mathrm{mf}}\right)
$$

with $\rho_{\mathrm{p}}$ and $\rho_{\mathrm{f}}$ being the particles and the fluid density, and $\varepsilon_{\mathrm{mf}}$ the dense phase porosity at minimum fluidization

(b)

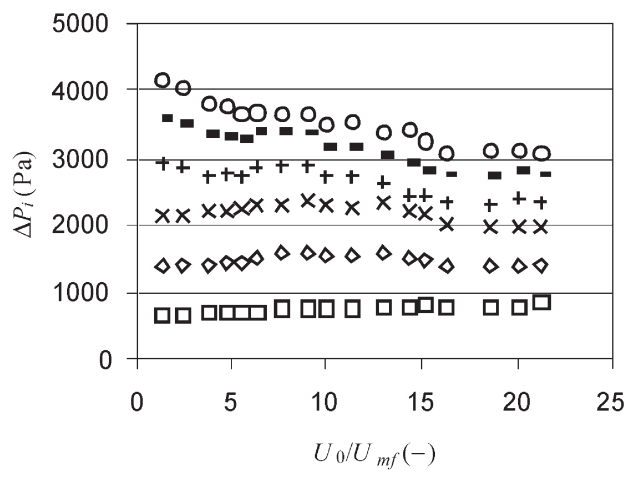

Figure 4. Typical evolution of the bed pressure drop using (a) 'p9x' and (b) 'dyn' distributor plates, for increasing values of $U_{0} / U_{\text {mf }}(\square$, first layer; $\diamond$, second; $\times$, third; +, fourth; -, fifth; 0 , sixth). 
conditions. As the objective is the analysis of the bed behaviour beyond the point of minimum fluidization conditions, and the measurement system is made between fixed probes, the reduction of the amount of solids must be accounted for by means of the introduction of the bubbles void fraction $\delta$, so that the resulting pressure drop is

$$
\frac{\mathrm{d} P}{\mathrm{~d} H}=\left(\rho_{\mathrm{p}}-\rho_{\mathrm{f}}\right) g\left(1-\varepsilon_{\mathrm{mf}}\right)(1-\delta)
$$

For the high gas velocities found in the experimental conditions, ca $20 U_{\mathrm{mf}}$ for these group B particles, it is necessary to account for the friction effects resulting from the collisions between particles and between particles and confining walls. These effects will be equated as a fraction of the dynamic force exerted, following a similar approach from Yerushalmi et al. (1978), so that the pressure drop owing to the drag exerted by the gas upon those particles can be expressed as

$$
\mathrm{d} P=\frac{1}{2} \lambda\left(\frac{U_{\mathrm{mf}}}{\varepsilon_{\mathrm{mf}}}-U_{\mathrm{p}}\right)^{2} \rho_{\mathrm{f}} \mathrm{d} N_{\mathrm{p}}
$$

where $U_{\mathrm{mf}}$ is the minimum fluidization velocity, $U_{\mathrm{p}}$ the particles velocity and $N_{\mathrm{p}}$ the number of particles in a bed section of thickness $\mathrm{d} H$, so that

$$
\frac{\mathrm{d} P}{\mathrm{~d} H}=\frac{3}{4} \lambda\left(\frac{U_{\mathrm{mf}}}{\varepsilon_{\mathrm{mf}}}-U_{\mathrm{p}}\right)^{2} \rho_{\mathrm{f}}\left(1-\varepsilon_{\mathrm{mf}}\right)(1-\delta) \frac{D^{2}}{d_{\mathrm{p}}^{3}}
$$

with $D$ the bed diameter and $d_{\mathrm{p}}$ and the average diameter of the particles. Finally, $\lambda$ accounts for the friction effects between the particles and the particles and the walls, and as a result of multiple set of experiments performed, shall be correlated with

$$
\lambda=1.5 \times 10^{-4}\left(\frac{U_{0}}{U_{\mathrm{mf}}}\right)^{1,5}
$$

This factor increases with increasing superficial velocity, as beyond stationary conditions the bed will produce a growing frequency of collisions, and the obtained values are within the range $10^{-2}-10^{-4}$ defined by Barth's (1954) model. In addition, results are in good agreement with former experimental results (Paiva et al., 2000).

In equation (5), the difference between the interstitial velocity, taken as $U_{\mathrm{mf}} / \varepsilon_{\mathrm{mf}}$ (supposing that the dense phase voidage remains constant above $U_{\mathrm{mf}}$ ) and the particle velocity $U_{\mathrm{p}}$, is its terminal velocity $U_{\mathrm{t}}$,

$$
U_{\mathrm{f}}-U_{\mathrm{p}} \equiv U_{\mathrm{t}}=\sqrt{\frac{4}{3} \frac{\rho_{\mathrm{p}} g d_{\mathrm{p}}}{C_{\mathrm{Dc}} \rho_{\mathrm{f}}}}
$$

According to the previous equation, $C_{\mathrm{Dc}}$ the drag coefficient for a cloud of particles, is calculated using the Wen and Yu (1966) correlation, quoted by Klinzing (1981):

$$
C_{\mathrm{Dc}}=C_{\mathrm{Ds}} \varepsilon_{\mathrm{mf}}^{-4,7}
$$

Back to equation (5), $\varepsilon_{\mathrm{S}}$ equals the product of the fraction of solids in the dense phase by the remainder of the fraction of bubbles regarding the whole bed,

$$
\varepsilon_{\mathrm{s}}=\left(1-\varepsilon_{\mathrm{mf}}\right)(1-\delta)
$$

Finally, the result of summing both hydrostatic head and friction loss contribution, equations (2) and (5), is:

$$
\frac{\mathrm{d} P_{\text {calc }}}{\mathrm{d} H}=\left[\left(\rho_{\mathrm{p}}-\rho_{\mathrm{f}}\right) g+\frac{3}{4} \lambda\left(U_{\mathrm{t}}-U_{\mathrm{p}}\right)^{2} \rho_{\mathrm{f}} \frac{D^{2}}{d_{\mathrm{p}}^{3}}\right] \varepsilon_{\mathrm{s}}
$$

where $U_{t}$ is calculated by means of equation (7). Consequently, the values of $\varepsilon_{\mathrm{s}}$ are those that make the dimensionless pressure drop $\Delta P^{+}$, a ratio between the experimental pressure drop values $\Delta P_{\text {exp }}$, and the calculated ones, equation (10), equal to unity:

$$
\Delta P^{+}=\frac{\Delta P_{\text {exp }}}{\Delta P_{\text {calc }}}
$$

The calculation procedure was then, by means of applying equations (2)-(10) to the experimental results of the sliced bed's pressure drop, determining $\varepsilon_{\mathrm{s}}$ so that equation (11) is satisfied. The average relative contribution of the frictional component of $\mathrm{d} P / \mathrm{d} H$ [equation (10)] is in the range of 0 to $45-60 \%$, for $U_{0}$ from 0.1 to $2.1 \mathrm{~m} \mathrm{~s}^{-1}$, growing with the reduction of the number of distributor orifices, the exception being the 'dyn' distributor plate.

Because the bed was divided into slices inside which the pressure drop evolution was studied, instead of measuring the bed pressure drop as if it was a whole entity, some particularities concerning the different regions along the bed height could be detected. These local characteristics are

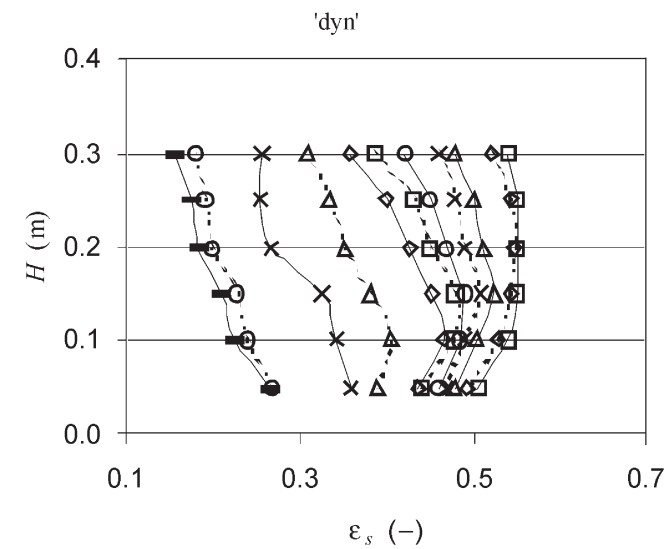

Figure 5. Evolution of the bed axial solids concentration, $\varepsilon_{\mathrm{s}}$, for values of $U_{0} / U_{\mathrm{mf}}\left(\square\right.$, solid line, $U_{0} / U_{\mathrm{mf}}=1 ; \diamond$, dashed line, $2 ; \Delta$, solid line, $3 ; \times$, dashed line, 4; , solid line, $5 ; \square$, dashed line, $7 ; \diamond$, solid line, $10 ; \triangle$, dashed line, $13 ; \times$, solid line, 17; $\bigcirc$, dashed line, 20). 
usually hidden when the analysis considers the bed as a sole entity.

Figure 5 shows the results obtained for the evolution of the fraction of solids with height, for several values of the ratio $U_{0} / U_{\mathrm{mf}}$ and distributor plates ' $\mathrm{p} 9 \mathrm{x}$ ' and 'dyn'. It must be stressed that at higher velocities the bed expands and, consequently, particles are displaced towards higher slices and thus cannot be accounted for in the lower slices of the bed, the ones under analysis.

$$
U_{0} / U_{m f}=1
$$

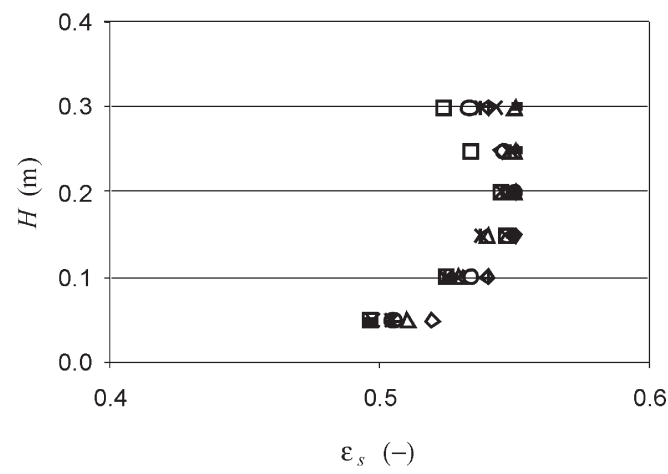

$U_{0} U_{m f}=6$

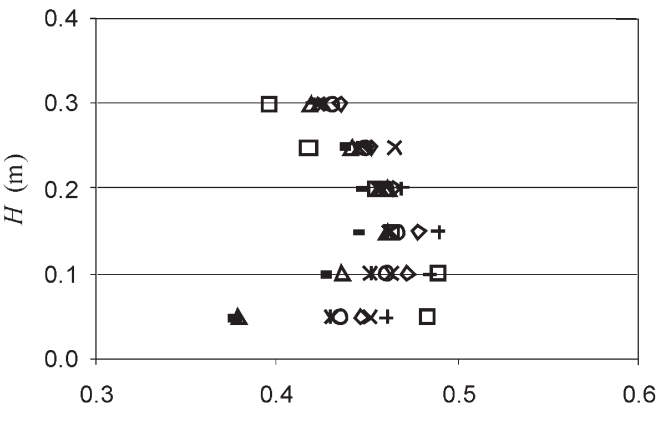

$\varepsilon_{s}(-)$

$U_{0} U_{m f}=13$

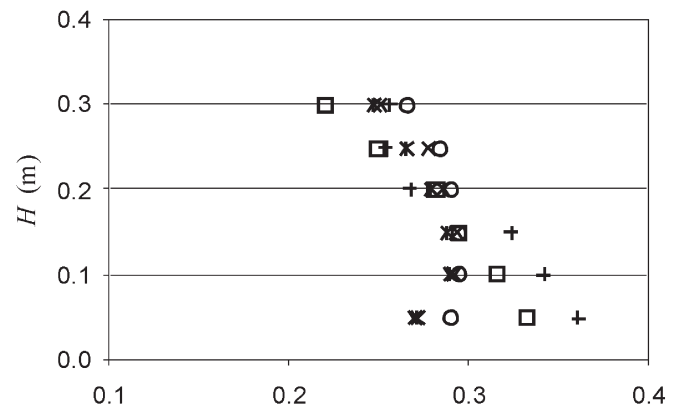

$\varepsilon_{s}(-)$
Therefore, as the fluidizing velocity increases, the local bottom solids concentration broadly decreases as expected. Nonetheless, at heights around $0.15 \mathrm{~m}$, mainly for the lower velocities, it reaches a maximum, and then decreases again. The trend described becomes evident in Figure 6, where the several tested distributors are compared for increasing velocity values, from 1 to $20 U_{0} / U_{\mathrm{mf}}$. At low fluidizing velocities, differences between the several distributors are minor. Nevertheless, the curves appear to have a similar
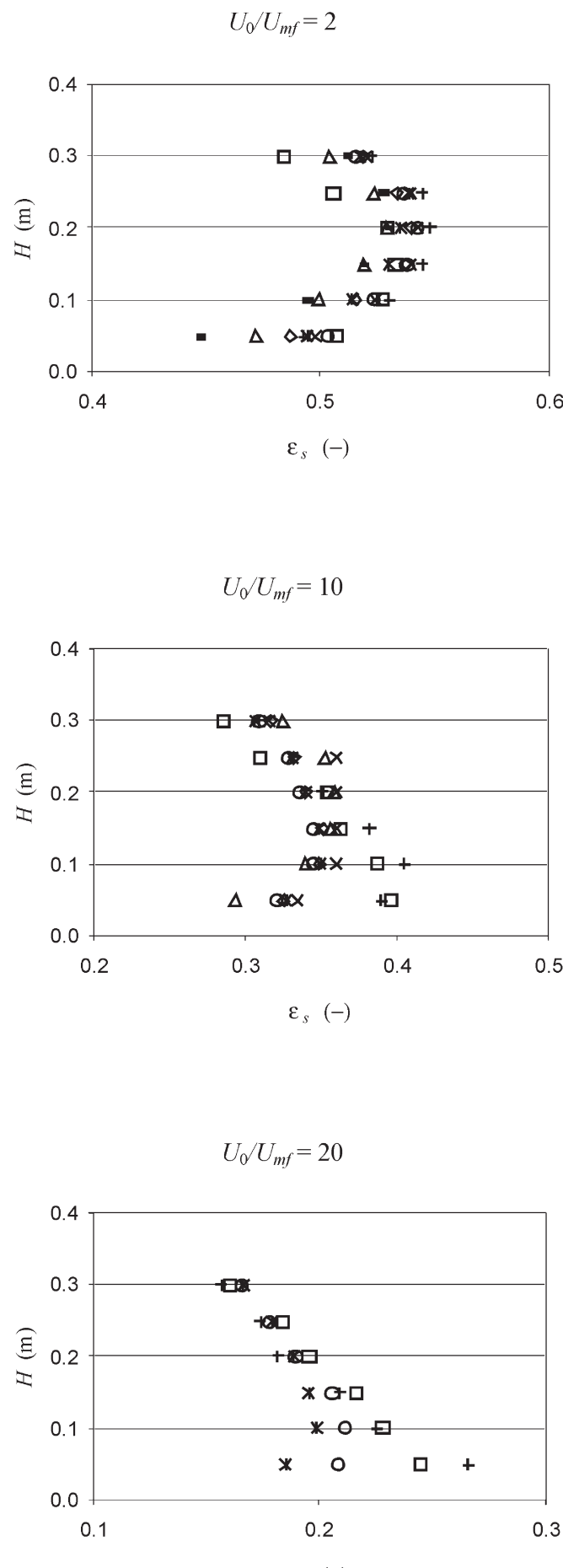

$\varepsilon_{s}(-)$

Figure 6. Axial solids concentration profiles, $\varepsilon_{\mathrm{s}}$, in the fluidized bed for various fluidization ratios of $U_{0} / U_{\mathrm{mf}}(\square$, 'ker'; o, 'p9x'; +, 'dyn'; *, 'p4x'; ×, 'p3x'; $\diamond$, 'p2x'; $\triangle$, 'p1x'; -, 'p0x'). 
behaviour to those described before, presenting a maximum solids concentration for values of $H$ in the interval $0.15-0.20 \mathrm{~m}$. Near the distributor orifices, where the influence of emerging gas jets strongly disrupts the uniform distribution of the solid phase, there is no distinction of the pattern of behaviour as a function of the used distributor. However, differences become increasingly apparent for higher fluidization velocities. Unlike the authors mentioned above (Svensson et al., 1993; Johnsson and Leckner, 1995; Zijerveld et al., 1997; Schlichthaerle and Werther, 1999; Malcus et al., 2000), who consistently report either a decrease or a constant value of the pressure drop in the bottom zone of the bed, the experimental results presented show the existence of a non-linear evolution for the group B particles. In particular, the lower pressure drop plates (namely 'ker' and 'p9x') reveal a distinct maximum value due to the presence of solids in the lower portion of that region of the bed, while the other plates keep showing the same typical pattern of behaviour. The higher the velocity of the jets, the more accentuated becomes the establishment of a local pressure reduction. This classical energy compensation has the effect of dragging the surrounding particles to this region, enhancing the solids downcoming flow, resulting in a growing accumulation closer to the gas distributor plate as the gas mass flow rate increases.

Figure 7 shows this trend as a function of superficial gas velocity. With the rise of gas velocity at the orifices, corresponding to larger jets with stronger dragging capabilities, the maximum solids concentration gets closer to the distributor plate with the increase of fluidizing gas flow. Although a decrease in the open area of the distributors causes a higher velocity at the orifices, their reduction in number also means a greater distance between them, so the effect of pressure compensation does not have such a strong spatial influence as in the case of the lower pressure drop plates. The drag over the surrounding particles no longer prevails, and as the jets high velocity gas flow cannot pass easily through the bed, the overall gas velocity decreases and consequently a pressure build-up takes place just above the gas distributor. This situation is hydrodynamically solved in an intermittent way (Svensson et al., 1993) when the bubbles are formed, or more adequately, where the bubbles are formed. A path is created through which the temporarily retained gas flow will pass (van der Schaaf et al., 1999), the pressure reduces and the solids concentration increases higher up the bed. This way, considering the whole bed, the traditional gas flow split between the dense phase flow, the visible bubble flow and the invisible bubble flow, is re-established.

\section{Dense Phase Voidage at the Bottom of the Bed}

There is another aspect that can be taken into consideration from the analysis of the pressure drop evolution inside the bed, the fluctuation of the emulsion porosity. Several references in the literature agree that calculated values of bubbles diameters and rising velocities using the model of Werther and Wein (1994) were in fairly good agreement with the void sizes found experimentally. Especially under conditions of superficial velocities typical for combustors (and for the group B particles widely used in those processes). Similar good results for the whole bed were obtained in the present work, with the range of particles

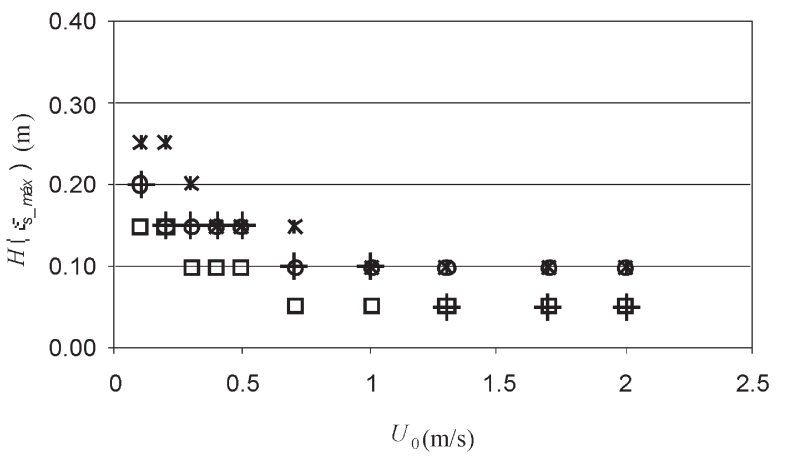

(a)

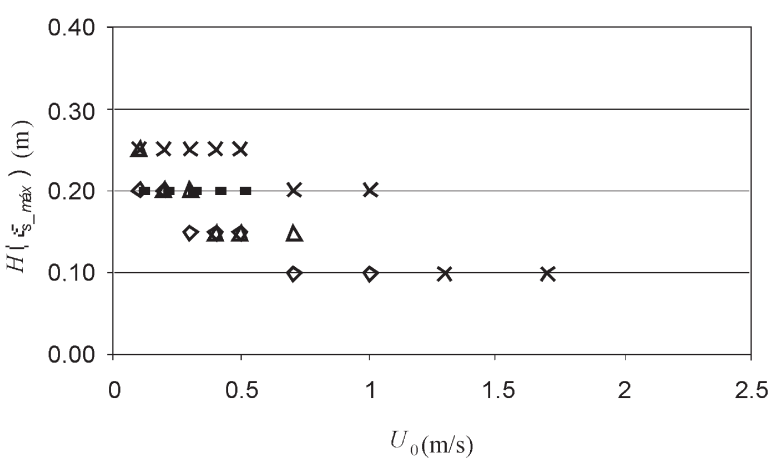

(b)

Figure 7. Height $H$ at which maximum solids concentration $\varepsilon_{\mathrm{s}}$ occurs, vs. superficial gas velocity $U_{0}$ : (a) $\square$, 'ker'; $\circ$, 'p9x'; +, 'dyn'; *, 'p4x'; (b) $\times$, 'p3x';, , 'p2x'; $\Delta$, 'p1x'; -, 'p0x'.

used in these experiments. The first layers revealed, however, some differences when using the lower pressure drop plates, as can be seen in Figure 8 (where those results are presented for the first and the sixth layer).

If the bottom bed is modeled according to the model of Werther and Wein (1994), by calculating the bubbles voidage $\delta$, with equation (12),

$$
\delta=1.45 A r^{-0.18} \frac{U_{0}-U_{\mathrm{mf}}}{\sqrt{U_{\mathrm{ba}}}}
$$

a good adjustment to the experimental results of the whole bed can be achieved, as can be observed in Figure 8, sixth layer. In equation (12), the bubble absolute velocity $U_{\mathrm{ba}}$, is (Werther and Wein, 1994)

$$
U_{\mathrm{ba}}=1.45 A r^{-0.18}\left(U_{0}-U_{\mathrm{mf}}\right)+0.71 v g^{0.5} d_{\mathrm{b}}
$$

where $v$ takes the value $2 \sqrt{ } D$ for $0.1<D<1.0 \mathrm{~m}$, and the evolution of the bubble diameter $d_{\mathrm{b}}$, with the height of the bed, is obtained through equation (14) (Werther and Wein, 1994):

$$
\frac{\mathrm{d}\left(d_{\mathrm{b}}\right)}{\mathrm{d} H}=\left(\frac{2 \delta}{9 \pi}\right)^{1 / 3}
$$

This will result in an implicit procedure concerning the calculation of $\delta$. Subsequently, an evolution of the dense phase porosity, or more appropriately, of the emulsion 

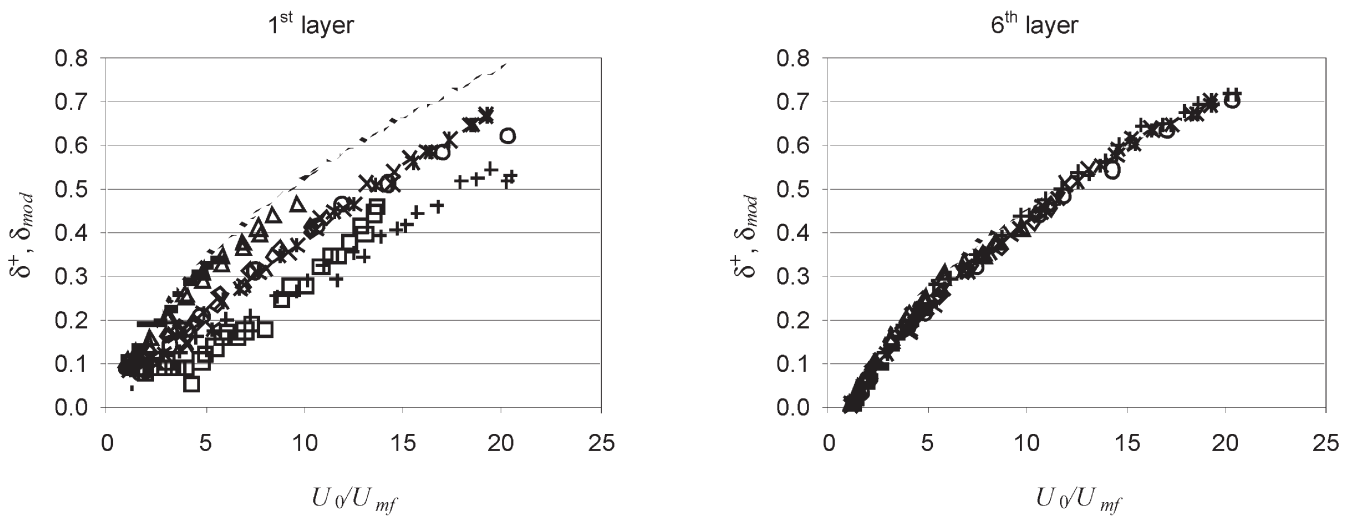

Figure 8. Evolution of the bed bubble fraction, $\delta_{\text {mod }}$, equation (8), and the resulting values for $\delta^{+}$, with different distributors, for several values of $U_{0} / U_{\mathrm{mf}}$

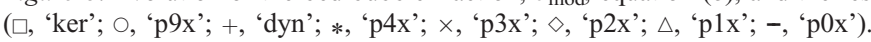

porosity $\varepsilon_{\mathrm{e}}$ (Figure 9), to borrow an expression from Kunii and Levenspiel (1969), can be estimated from

$$
\varepsilon_{\mathrm{e}}=\varepsilon_{\mathrm{mf}} \pm \Delta \varepsilon=1-\frac{1-\delta}{1-\delta^{+}}\left(1-\varepsilon_{\mathrm{mf}}\right)
$$

where $\delta$ represents the values of the fraction of bubbles calculated from equations (12)-(14) and $\delta^{+}$the values that make $\Delta P^{+}$equal to $1 ; \Delta \varepsilon$ represents the range of variation of the dense phase voidage around the incipient conditions value.

The results of applying this expression to the experimental data reveal a change in the porosity of the emulsion, away from the postulated constant dense phase porosity $\varepsilon_{\mathrm{mf}}$, especially in the lower part of the bed, as the fluidization velocity increases and reaches the transition from bubbling to turbulent regime. The difficulty in determining experimentally the dense phase flow is the reason why the usual practice has been to calculate its value based on the two-phase flow premises, forcing the invisible bubble's flow to accommodate discrepancies between expected and detected experimental behavior. This would explain, on the other hand, why the experimentally based calculated values of the bubbles void fraction $\delta^{+}$, were different from the Werther and Wein (1994) model results for the first layers of the bed, meaning that the

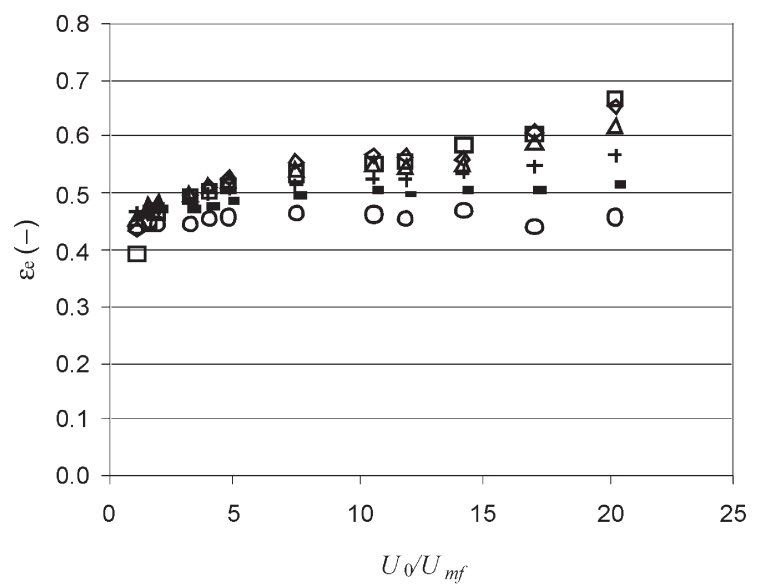

Figure 9. Evolution of the porosity of the emulsion, $\varepsilon_{\mathrm{e}}$, equation (11), for several values of $U_{0} / U_{\mathrm{mf}}$ ( $\square$, layer $1 ; \diamond$, layer $2 ; \Delta$, layer $3 ;+$, layer 4 ; -, layer 5 ; $\circ$, layer 6 ) need to allow the passage of the excess of air was not completely performed by the bubbles phase (either visible or invisible), but that the dense phase widens to accommodate the extra gas flow, a dynamic phenomenon described by Wilhelm and Kwauk (1948), Lewis et al. (1949) and Wen and Yu (1966), especially when moving nearer the feeding point of the fluidizing medium. As for the upper layers, values of porosity are almost constant, approaching 0.45 , which, for these $0.355-0.425 \mathrm{~mm}$ group B silica ballotini is the expected values, meaning that the air flow has a more stable path condition.

\section{CONCLUSIONS}

An investigation of the bottom zone of a fluidized bed, using three types of distributor plates, was performed using pressure drop measurements. The results show that the flow changes with variation of the operating conditions. The measurements at several different equal heights show changes in the hydrodynamic behaviour of the gas-solid suspension. For the tested group B particles and static bed height, there is no linear decrease, or even a sustained uniform trend towards a decrease of the solids concentration with height in that region of the bed. Furthermore, using a model for the calculation of the fraction of bubbles, the results include the detection of a fluctuation in the values of the porosity of the emulsion, with height and with the fluidization velocity.

\section{NOMENCLATURE}

$A$
$d_{\mathrm{b}}$
$d_{\text {or }}$
$d_{\mathrm{p}}$
$D$
$F$
$g$
$H$
$I_{r}$
$L$
$N_{\text {or }}$
$P$
$T$
$U_{0}$
$U_{\mathrm{ba}}$
$U_{\mathrm{m}}$
$U_{\mathrm{t}}$ bed cross-sectional area, $\mathrm{m}^{2}$

bubble diameter, $\mathrm{m}$

orifice diameter, $\mathrm{m}$

average particle diameter, $\mathrm{m}$

internal bed diameter, $\mathrm{m}$

drag force, $\mathrm{N}$

gravitational acceleration, $\mathrm{m} \mathrm{s}^{-2}$

vertical distance from gas distributor to bed free surface, $\mathrm{m}$ global uncertainty associated to a result or to a variable $r$

height of the unit, $m$

number of orifices of the distributor plate

local atmospheric pressure, $\mathrm{Pa}$

ambient temperature, ${ }^{\circ} \mathrm{C}$

superficial fluidization velocity, $\mathrm{m} \mathrm{s}^{-1}$

mean bubble absolute rise velocity, $\mathrm{m} \mathrm{s}^{-1}$

minimum fluidization velocity, $\mathrm{m} \mathrm{s}^{-1}$

terminal velocity, $\mathrm{m} \mathrm{s}^{-1}$ 
$\begin{array}{ll}U_{\mathrm{p}} & \text { particle velocity, } \mathrm{m} \mathrm{s}^{-1} \\ x_{i} & \text { mass fraction in the } i \text { interval }\end{array}$

Greek symbols

$\delta \quad$ bubble fraction, equation (12)

$\delta^{+} \quad$ bubble fraction value that yields to equation (11)

$\Delta P \quad$ pressure drop, $\mathrm{Pa}$

$\Delta P^{+} \quad$ dimensionless pressure drop, equation (11)

$\Delta P_{\text {dist }} \quad$ distributor pressure drop, $\mathrm{Pa}$

$\Delta P_{s j} \quad$ slice pressure drop, $\mathrm{Pa}$

$\Delta P_{\mathrm{t}} \quad$ total bed pressure drop, $\mathrm{Pa}$

$\Delta \varepsilon \quad$ variation of the dense phase voidage around the incipient conditions value

$\varepsilon_{\mathrm{e}} \quad$ emulsion void fraction

$\varepsilon_{\mathrm{mf}} \quad$ void fraction at minimum fluidization conditions

$\varepsilon_{\mathrm{s}} \quad$ fraction of solids

$\lambda \quad$ impact and attrition factor

density, $\mathrm{kg} \mathrm{m}^{-3}$

standard mean deviation

parameter in equation (13)

Dimensionless numbers

Ar Archimedes number, $\rho_{\mathrm{f}}\left(\rho_{\mathrm{p}}-\rho_{\mathrm{f}}\right) g d_{\mathrm{p}}^{3} / \mu^{2}$

$C_{\mathrm{D}} \quad$ drag coefficient, $F_{\mathrm{D}} / \rho U^{2} A$

$C_{\mathrm{Dc}} \quad$ corrected drag coefficient, $C_{\mathrm{Ds}} \varepsilon_{\mathrm{mf}}^{-4,7}$

$C_{\mathrm{Ds}} \quad$ drag coefficient for a single particle

\section{Subscripts}

$0 \quad$ relative to the bed free surface

b bubble

c cluster

calc calculated

D drag

dist distributor

exp experimental

f fluid

$i \quad$ layer

j slice

$\mathrm{mf} \quad$ relative to minimum fluidization conditions

or relative to the number of orifices in the distributor plate

$\mathrm{p} \quad$ relative to the particles

single

total

Superscripts

$+$

relative to the dimensionless bed pressure drop, equation (11) relative to the normalization of the standard mean deviation using the maximum value for a specific run

\section{REFERENCES}

Bai, D., Shibuya, E., Masuda, Y., Nakawaga, N. and Kato, K., 1996, Flow structure in a fast fluidized bed, Chem Eng Sci, 51: 997-966.

Barth, W., 1954, Chem Ing Tech, 20(1): 29-32, in Pneumatic Conveying of Solids, Marcus, R.D., Leung, L.S., Klinzing, G.E. and Rizk, F. (eds) (Chapman and Hall, London, UK).

Bolton, L.H. and Davidson, J.F., 1988, Recirculation of particles in fast fluidized risers, in Circulating Fluidized Bed Technology II, Basu, P. and Large, J.F. (eds) (Pergamon Press, Oxford, UK), pp 139-146.

Brereton, C.M.H. and Grace, J.R., 1993, Microstructural aspects of the behavior of circulating fluidized beds, Chem Eng Sci, 48: 2565-2572.
Coleman, H.W. and Steele, W.G., 1999, Experimentation and Uncertainty Analysis for Engineers (Wiley, New York, USA).

Geldart, D. and Baeyens, J., 1985, The design of distributors for gasfluidized beds, Powder Technol, 42(1): 67-78.

Holman, J.P., 1994, Experimental Methods for Engineers, 6th edition (McGraw-Hill, New York, USA).

Johnsson, F. and Leckner, B., 1995, Vertical distribution of solids in a circulating fluidized bed in a circulating fluidized bed furnace, in Proceedings of FBC 13, Heinschel, K.J. (ed), 7-10 May, Orlando, FL, p 671.

Klinzing, G.E., 1981, Gas-Solid Transport (McGraw-Hill, New York, USA).

Kunii, D. and Levenspiel, O., 1969, Fluidization Engineering (Krieger, New York, USA).

Lewis, W.K., Gilliland, E.R. and Bauer, W.C., 1949, Characteristics of fluidized particles, Ind Eng Chem, 41: 1104-1117.

Malcus, S., Chaplin, G. and Pugley, T., 2000, The hydrodynamics of the high-density bottom zone in a CFB riser analyzed by means of electrical capacitance tomography (ECT), Chem Eng Sci, 55: 4129-4183.

Paiva, J.M., Pinho, C. and Figueiredo, R., 2000, Distributor plate influence on fluidization quality, measuring pressure drop evolution in adjacent slices through the bed, in Proceedings of the FEDSM2000 - ASME Fluids Engineering Division Summer Meeting, 11-15 June, Boston, MA (Multi-media CD-ROM FEDSM2000-1026.ps) (ASME, New York, USA).

Schlichthaerle, P. and Werther, J., 1999, Axial pressure profiles and solid concentration distributions in the CFB bottom zone, in Circulating Fluidized Bed Technology VI, Werther, J. (ed.) (Dechema, Germany), pp 185-190.

Schnitzlein, M.G. and Weinstein, H., 1988, Design parameters determining solids hold-up in fast fluidized bed system, in Circulating Fluidized Bed Technology II, Basu, P. and Large, J.F. (eds) (Pergamon Press, Oxford, UK), pp 205-211.

Sun, G., Chao, Z, Fan, Y. and Shi, M., 1999, Hydrodynamic behavior in the bottom region of a cold FCC riser, in Circulating Fluidized Bed Technology VI Werther, J. (ed.) (Dechema, Germany), pp 179-184.

Svensson, A., Johnsson, F. and Leckner, B., 1993, Fluid-dynamics of the bottom bed of circulating fluidized bed boilers, in Proceedings of the 12th International Conference on Fluidized Bed Combustion, Rubow, L. (ed) (ASME, New York, USA), pp 887-897.

Svensson, A., Johnsson, F. and Leckner, B., 1996a, Bottom bed regimes in a circulating fluidized bed boiler, Int J Multiphase Flow, 22(6): 1187-1204.

Svensson, A., Johnsson, F. and Leckner, B., 1996b, Fluidization regimes in non-slugging fluidized beds: the influence of pressure drop across the air distributor, Powder Technol, 86: 299-312.

van der Schaaf, J., Schouten, J.C., Johnsson, F. and van den Bleek, C.M., 1999, Bypassing of gas through bubble chains and jets in circulating fluidized beds, in Proceedings of 6th International Conference on Circulating Fluidized Beds, Werther, J. (ed) (Dechema, Frankfurt am Main, Germany), pp 47-52.

Wen, C.Y. and Yu, Y.H., 1966, Mechanics of fluidization, Chem Eng Prog Symp Ser, 62(62): 100-111.

Werther, J. and Wein, J., 1994, Expansion behavior of gas fluidized beds in the turbulent regime, AIChE Symp Ser, 301(90): 31-44.

Wilhelm, R.H. and Kwauk, M., 1948, Fluidization of solid particles, Chem Eng Prog, 44: 201-218.

Yerushalmi, J., Cankurt, N.T., Geldart, D. and Liss, B., 1978, Flow regimes in vertical gas-solid contact systems, AIChE Symp Ser, 74(176): 1-13.

Zijerveld, R.C., Koniuta, A., Johnsson, F., Marzocchella, A., Schouten, J.C. and van den Bleek, C.M., 1997, Axial solids distribution and bottom bed dynamics for circulating fluidized bed combustor application, AIChE Symp Ser, 93(318): 97-102.

The manuscript was received 11 June 2002 and accepted for publication after revision 10 September 2003. 